\title{
Development of a comprehensive Blast-Related Auditory Injury Database (BRAID)
}

\author{
Antony R. Joseph, AuD, PhD; ${ }^{*}{ }^{*}$ Jaime L. Horton, MPH; $^{2}$ Mary C. Clouser, MPH, PhD; ${ }^{2}$ Andrew J. MacGregor, \\ PhD; ${ }^{2}$ Michelle Louie, BA; ${ }^{2}$ Michael R. Galarneau, MS, NREMT ${ }^{2}$ \\ ${ }^{1}$ Navy Environmental and Preventive Medicine Unit Five, San Diego, CA; ${ }^{2}$ Medical Modeling, Simulation, and Mis- \\ sion Support Department, Naval Health Research Center, San Diego, CA
}

\begin{abstract}
The Department of Defense Hearing Conservation Program provides specific guidance for service components to prevent occupational hearing loss; however, it does not specifically contend with the unique noise exposures observed in the theater of war, such as blasts and explosions. In order to examine the effects of blast injury on hearing sensitivity, we developed a large database composed of demographic, audiometric, point of injury, and medical outcome data, with the primary aim of developing a long-standing and integrated capability for the surveillance, assessment, and investigation of blast-related hearing outcomes. Methods used to develop the dataset are described. Encompassing more than 16,500 Navy and Marine Corps personnel, the Blast-Related Auditory Injury Database (BRAID) includes individuals with a blast-related injury and nonblast control subjects. Using baseline and postdeployment hearing threshold data, a retrospective analysis of the cohort revealed that the rate of hearing loss for the injured servicemembers was $39 \%$. The BRAID will be useful for studies that assess hearing patterns following deployment-related injury, such as blast exposures, that facilitate exploration of health outcomes and whether they are predictive of audiometric disposition and that help establish hearing loss prevention strategies and program policies for affected military commands and servicemembers.
\end{abstract}

Key words: blast exposure, blast injury, Blast-Related Auditory Injury Database, BRAID, hearing conservation, hearing loss, noise exposure, noise-induced hearing loss, occupational hearing loss, servicemembers.

\section{INTRODUCTION}

Exposure to hazardous noise, such as constant, intermittent, impact, impulse, blast, or a combination of these, may result in temporary or persistent noise-induced hearing loss (NIHL) and tinnitus. NIHL and tinnitus present a problematic public health burden that has been estimated to affect 22 million Americans [1]. The Armed Forces have engaged Hearing Conservation Programs (HCPs) since the 1960s. This fact should not suggest that the military has mastered the maze of hearing conservation inef-

\footnotetext{
Abbreviations: AIS = Abbreviated Injury Scale, BRAID = Blast-Related Auditory Injury Database, DMDC = Defense Manpower Data Center, DOD = Department of Defense, DOEHRS = Defense Occupational and Environmental Health Readiness System, DOEHRS-DR = DOEHRS-Data Repository, DOEHRS-HC $=$ DOEHRS-Hearing Conservation, EMED = Expeditionary Medical Encounter Database, HCP $=$ Hearing Conservation Program, HL = hearing level, ICD-9 = International Classification of Diseases-9th Revision, LFPTA = lowfrequency pure-tone average, MDR = Military Health System Data Repository, MTF = military treatment facility, NIHL = noise-induced hearing loss, OSHA = Occupational Safety and Health Administration, $\mathrm{PTA}=$ pure-tone average, $\mathrm{SD}=$ standard deviation, VA = Department of Veterans Affairs.

*Address all correspondence to Antony R. Joseph, AuD, PhD; Illinois State University, Communication Sciences and Disorders, Campus Box 4720, Normal, IL 61790; 309438-7061; fax: 309-438-5221. Email: arjoseph@ilstu.edu http://dx.doi.org/10.1682/JRRD.2015.02.0031
} 
ficiencies. To the contrary, military culture adds an additional layer of complication to audiologic management of servicemembers, making avoidance of hearing loss or even slight shifts in hearing sensitivity increasingly difficult. The Department of Defense (DOD) HCP [2] provides specific guidance for service branches in an effort to mitigate occupational hearing loss; however, it does not specifically address unique noise exposures observed in the theater of war. Combat noise exposure, which by military regulation does not mandate hearing protection, is a problem scenario for the hearing conservationist because many of the high-level operational military noises are immutable.

The gold standard method of surveillance for Occupational Safety and Health Administration (OSHA) [3] and DOD HCPs is the audiometric hearing threshold test-the audiogram. Both OSHA and DOD require annual audiograms, also called pure-tone tests, which include test frequencies from 500 to $6,000 \mathrm{~Hz}$. The principal difference between OSHA and DOD is that follow-up testing is required in the DOD system whenever hearing shift has been observed, but follow-up is only recommended by OSHA. Further, most OSHA-based programs apply agecorrection in their threshold-shift calculations, but this is not permitted in the DOD because age-correction expunges threshold shift in individuals and thus reduces the sensitivity of audiometric monitoring. Given the migratory nature of combat military personnel, it is imperative to capture audiometric screenings consistently in order to identify hearing shift as early as possible; individuals deployed to battle zones are increasingly at risk for NIHL, tinnitus, and other otologic injuries [4]. The effects of blast exposure on the auditory system are well documented in the literature and suggest varying audiometric outcome patterns [5-9].

The ear is the most susceptible to and often the first organ to sustain blast injury [7,10-12]. Factors such as the position of the ear in relation to the explosion, the state of the ear canal, and whether the explosion occurred in a confined space can influence the severity of damage to the ear $[11,13]$. The most visible type of blast-induced auditory injuries occur in the physical structures of the middle and inner ear, which include tympanic membrane perforations, ossicular disruptions, and symptoms generated from insult to the vestibular components [5,12,1417]. Damage to auditory components of the inner ear is of primary interest because it may be permanent and cause persistent symptoms of tinnitus [18-20] and hear- ing loss $[6,17,21-23]$. Blast-related middle-ear damage has been associated with perforation of the tympanic membrane, although spontaneous recovery has been observed in the vast majority of injured patients $[12,14,24]$. Similarly, inner-ear temporary hearing shift caused by blast can improve slightly, but has not been reported to recover as predictably as middle-ear injuries.

The manner in which blast exposure persistently affects hearing sensitivity in the short- and long-term has not been adequately represented in the literature. Most reports have been directed at small samples involving civilian personnel. Several studies have reported minimal sensorineural hearing loss in blast-exposed individuals [5-9,25]; however, reversible conductive hearing losses have been more consistently identified. The greatest source of information on symptoms immediately following primary blast injury of the ear may be found in civilian literature [26]. Blast injury among civilians, however, is uncommon and generally studied as a consequence of terrorism or industrial accidents. Sample sizes in these studies are relatively small, and the prevalence of symptoms among all exposed persons is unknown. Such reports contain primarily descriptive statistics of presenting injuries and symptoms.

Assessing the progression of audiologic symptoms is of primary importance in determining hearing-related morbidity. The most common symptoms reported in victims of blast are tinnitus and hearing loss, with a significant proportion of patients reporting concomitant tinnitus and hearing loss. Cave et al. determined that only 63 percent of their sample of 258 blast-injured patients had a predeployment audiogram and reported that approximately 50 percent of their subjects demonstrated persistent hearing loss [13]. They attributed this higher rate to the fact that their data were extracted from an audiology clinic database. Mrena et al. assessed the otologic and audiologic outcomes of 29 patients treated for ear injury after a Finland shopping mall explosion [27]. They found that 66 percent reported tinnitus as their initial symptom, and 55 percent reported hearing loss. Twelve of the twenty-nine patients (41\%) experienced both tinnitus and hearing loss.

It is unclear which of the audiometric patterns reported by investigators [5-9] can be associated with war-related blast outcomes. Lew et al. found that 62 percent of combat Veterans complained of hearing loss, while 38 percent reported tinnitus [7]. It is unknown whether hearing loss and tinnitus in these Veterans is a 
result of central auditory pathway disorder [28] or injury to the peripheral auditory system (e.g., cochlear). A number of studies have shown that blast exposure can result in damage to the hearing mechanism, but this is not consistently reflected as hearing loss in audiometric-threshold data, making evaluation of patients using a dual-sensory methodology worthwhile [29-30]. In a study of 250 Veterans, Oleksiak et al. reported that 87 percent of subjects had a complaint about hearing, and when exposed to blast, claimed to have increased auditory problems [31]. Tinnitus was reported in 76 percent of their subjects, while 49 percent had a diagnosis of conductive sensorineural hearing loss or central auditory dysfunction. Subclinical levels of auditory dysfunction were indicated in 24 percent of the sample [31]. Altogether, studies have not been in agreement regarding the frequency of permanent hearing loss and hearing shift rates, but because the majority of these investigations consisted of small sample sizes, it is unclear what the definitive rate of permanent loss is in a large, relatively homogenous sample.

Disability reports from the Department of Veterans Affairs (VA) have estimated that the cost of hearing loss increased more than tenfold from 1994 to 2011 [32], exceeding \$1 billion annually. Recent reports have identified tinnitus and hearing loss as the most common VA service-connected disabilities [20,33]. A hearing loss cost-probability model demonstrated that a typical retired operational servicemember would cost the government almost $\$ 14,000$ for hearing loss over his or her life span [34]. However, the exact cost of compensation for hearing loss and tinnitus is unclear because of the method used to compute VA disability. To compound the problematic nature of this issue, there is a shortage of quality epidemiologic data on adventitious hearing loss in the general population [35].

Our primary aim was to develop a long-standing and integrated capability for the surveillance, assessment, and investigation of blast-related hearing outcomes. Focused on minimizing the limitations observed in previous studies, our immediate goal was to use the database to describe the deployment-injured population with audiometric data in the Defense Occupational and Environmental Health Readiness System (DOEHRS) and determine the rate of hearing loss in this retrospective cohort. Future goals include using the database to track health outcomes and gain an understanding of whether they are predictive of audiometric disposition.

\section{METHODS}

\section{Study Population}

All Navy and Marine Corps personnel who had a deployment-related injury captured in the Expeditionary Medical Encounter Database (EMED), a deployment confirmed by the Defense Manpower Data Center (DMDC), and at least one valid audiogram in the DOEHRS-Data Repository (DOEHRS-DR) database from 2001 to 2013 were included in the Blast-Related Auditory Injury Database (BRAID). The EMED has been described in detail elsewhere [36]. Briefly, the EMED provides clinical data across the spectrum of medical care delivered in the operational setting. All available audiometric data for injured sailors and marines were extracted from the DOEHRS-DR database, which is discussed in detail in the next section. Relevant demographic, military, and health information was extracted from the DMDC database and the Military Health System Data Repository (MDR). The DMDC is the central source for identifying information on military personnel and was used to gather demographic and service-related information (https://www.dmdc.osd.mil/). The MDR is the centralized data repository that captures, archives, validates, integrates, and distributes DOD healthcare data. Data are received from DOD's worldwide network of more than 260 healthcare facilities and also from non-DOD data sources (http://www.health.mil/).

There were 18,250 Navy and Marine Corps personnel with coded deployment injuries in EMED. Only 3 percent $(n=525)$ had no recorded audiograms in the DOEHRS-DR. Compared to the group with audiograms, this group consisted of significantly more Reserve/ National Guard members (68\% vs $14 \%, p<0.001$ ), who were generally older, of higher rank, and a higher percentage of Navy personnel. After excluding those with no audiograms ( $n=525)$ and deaths $(n=512)$, there were 17,213 subjects with 56,010 audiograms between 2001 and 2013 in the DOEHRS-DR system. A total of 4,494 (8\%) of the audiograms were classified as unreliable, inaccurate, or associated with middle-ear obstruction and were removed based on our exclusion criteria outlined in the next section, resulting in the removal of another 688 subjects. The remaining 16,525 subjects represented 51,516 audiograms, 96 percent $(16,525 / 17,213)$ of the original subjects and 92 percent $(51,516 / 56,010)$ of the composite of audiometric records. 


\section{Audiometric Data}

The Navy and Marine Corps Public Health Center provides oversight of the DOEHRS-Hearing Conservation (DOEHRS-HC) and DOEHRS-DR (www.med.navy.mil/ sites/nmcphc). Personnel who are eligible and enrolled in the HCP are tested annually by certified Navy Hearing Conservation Technicians in certified single- or multisubject acoustic test enclosures. Pure-tone air conduction testing is administered using TDH-39 supra-aural headphones (Telephonics Corporation; Farmingdale, New York) connected to a Benson Medical Instruments CCA-200 computer-driven audiometer (Benson Medical Instruments; Minneapolis, Minnesota), which is acoustically calibrated annually [37]. Audiometers receive a daily functional check and biological calibration using the BAS200 simulator (Benson Medical Instruments). Daily calibration data are stored in DOEHRS-HC or printed for periodic compliance inspections. Subjects respond to pure-tone stimuli using a hand switch. Threshold data are collected in CCA-200 and transferred by the technician to the DOEHRS-HC software for storage, printing, and upload to the DOEHRS-DR. After the hearing test, personnel are counseled on findings and scheduled for a confirmation retest whenever hearing shift or baseline revision is indicated. Otoscopic visual inspection of the ears is conducted at the discretion of the HCP clinic supervisor, typically after a threshold shift or hearing loss is evident on the audiogram and whenever a referral is indicated.

The DOEHRS-DR provided all audiometric test dates and hearing thresholds for left and right ears at six test frequencies: 500, 1,000, 2,000, 3,000, 4,000, and $6,000 \mathrm{~Hz}$ [37]. Problematic audiometric data were excluded from the database. Missing hearing thresholds, data entry errors, and indications of "no response" resulted in removal of the subject's entire audiogram, both left and right ear data. Hearing thresholds with interaural differences of $50 \mathrm{~dB}$ or more resulted in exclusion of the affected audiogram because these disparities require special consideration, such as clinical referral for masking. When thresholds were greater than $20 \mathrm{~dB}$ on the hearing level (HL) scale (dB HL) and exhibited a ratio of low-frequency pure-tone average (LFPTA; 500 2,000 Hz) over high-frequency pure-tone average (PTA) $(3,000-6,000 \mathrm{~Hz})$ that was $\geq 1.5$ for the same ear, the subject's audiogram was disqualified because this configuration would not be associated with hazardous noise exposure. A low-to-high-frequency PTA ratio of 1.5 or greater indicates that $500-2,000 \mathrm{~Hz}$ thresholds are mark- edly poorer than $3,000-6,000 \mathrm{~Hz}$ thresholds, which is consistent with a low-frequency middle-ear problem. Audiograms with an absolute value LFPTA difference between ears that exceeded $45 \mathrm{~dB}$ were excluded for the same reason. For example, if the left ear LFPTA is $20 \mathrm{~dB}$ and the right ear LFPTA is $70 \mathrm{~dB}$, the absolute value difference would be $50 \mathrm{~dB}$, which may point to audiometric masking, unreliable data, conductive hearing loss, or other conditions unrelated to noise exposure. If a subject had multiple hearing tests recorded on the same day, only one audiogram was retained and all other test data for that date were excluded. To retain the most pertinent audiogram of the day, we used the DOEHRS-DR numeric classification, which effectively captures the purpose of each hearing test. Quality assurance checks were performed, and 100 percent of excluded audiograms were reviewed by a licensed and certified audiologist and Council for Accreditation for Occupational Hearing Conservation Professional Supervisor of the Audiometric Monitoring Program to ensure adherence to exclusion criteria for problematic DOEHRS-HC threshold data.

\section{Injury Data}

The EMED is designed to collate information from multiple points of care for each subject, beginning on the battlefield and contiguous battalion aid stations and culminating with military treatment facilities (MTFs) that provide tertiary care [38]. Variables contained in the EMED include date of injury, Abbreviated Injury Scale (AIS) score, Injury Severity Score, mechanism of injury (e.g., blast, gunshot wound), description of injury, and International Classification of Diseases-9th Revision (ICD-9) code of clinical diagnosis. Demographic and military-specific variables included in the database are service branch, rank, occupational specialty, sex, and date of birth. Follow-up inpatient and outpatient medical data were obtained from the MDR, which provides observations from DOD MTFs and TRICARE-approved service providers. Diagnostic information was represented by ICD-9 codes extracted from each subject's electronic health record. After matching the EMED and DOEHRSDR data, we conducted an extensive examination of hearing threshold and health outcome data recorded before and after injury.

\section{Statistical Analyses}

Hearing outcomes were calculated from the audiometric data using standard clinical definitions and the 
experience of a senior occupational audiologist. Severity, type, and site of injuries incurred by the study population were compared by battle and nonbattle injury using chisquare statistics. Data analysis and management were performed using SAS, version 9.3 (SAS Institute Inc; Cary, North Carolina).

\section{RESULTS}

Table 1 is a display of the demographic characteristics of subjects with reliable audiometric data. Our study population of injured servicemembers with available audiometric data was predominantly male (97\%) and enlisted in the Marine Corps, with a mean \pm standard deviation (SD) age of $24.0 \pm 5.7 \mathrm{yr}$ at the time of firstrecorded injury. The majority (95\%) of subjects were prepresbycusic, classified as $\leq 36 \mathrm{yr}$. More than 93 percent of the group was enlisted, primarily midlevel and junior enlisted personnel. Occupationally, the distribution of infantry and noninfantry personnel was equivalent, and tinnitus was reported at a rate that was similar to what is observed in the general population.

Figure 1 demonstrates that the majority of the sample $(67 \%)$ had from one to three audiograms in the DOEHRS-DR. Remaining subjects (33\%) had between 4 and 19 audiograms on record. This produced a rightskewed distribution, with a median of two audiograms. Figure 2 indicates that over the 12 yr period of this investigation, 89 percent of the personnel who went into the combat zone and recorded an injury there had an audiogram in DOEHRS-DR from prior to their injury. Over this same period, 70 percent of the sample had an audiogram in the DOEHRS-DR from after their injury. The diagram shows that almost 60 percent of the sample had both a pre- and postinjury audiogram in the DOEHRS-DR and more than a third of the group had multiple audiograms in the DOEHRS-DR from after their injury date.

The BRAID cohort had a mean \pm SD of $2.7 \pm 3.4$ injuries overall per individual. All medically documented injuries are shown in Table 2 by type of injury (battle vs nonbattle). Slightly more than half the cohort had at least one injury on record, and 14 percent had five or more. Not unexpectedly, battle and nonbattle injuries were significantly different by site, type, and severity. Battle injuries were mostly caused by blasts (78\%; data not shown) and consisted primarily of open wounds to the head, neck,
Table 1.

Characteristics of deployment-injured Navy and Marine Corps personnel included in the Blast-Related Auditory Injury Database with audiometric data from 2001 to $2013(N=16,525)$.

\begin{tabular}{|c|c|c|}
\hline Characteristic & $n$ & $\%$ \\
\hline Male & 16,025 & 97.0 \\
\hline Female & 500 & 3.0 \\
\hline \multicolumn{3}{|l|}{ Age at Time of Injury $(\mathrm{yr})^{*}$} \\
\hline$<21$ & 3,918 & 23.8 \\
\hline $21-28$ & 9,814 & 59.5 \\
\hline 29-36 & 1,877 & 11.4 \\
\hline $37-44$ & 698 & 4.2 \\
\hline$>44$ & 175 & 1.1 \\
\hline \multicolumn{3}{|l|}{ Pay Grade } \\
\hline E1-E3 & 3,273 & 19.8 \\
\hline E4-E6 & 10,840 & 65.6 \\
\hline E7-E9 & 1,244 & 7.5 \\
\hline Officer & 1,123 & 6.8 \\
\hline Unidentified & 45 & 0.3 \\
\hline \multicolumn{3}{|l|}{ Occupation } \\
\hline Noninfantry & 8,801 & 53.3 \\
\hline Infantry & 7,724 & 46.7 \\
\hline \multicolumn{3}{|l|}{ Service Branch } \\
\hline Marine Corps & 15,046 & 91.1 \\
\hline Navy & 1,479 & 9.0 \\
\hline \multicolumn{3}{|l|}{ Service Component } \\
\hline Active Duty & 14,164 & 85.7 \\
\hline Reserves/National Guard & 2,361 & 14.3 \\
\hline \multicolumn{3}{|l|}{ Battle Injury } \\
\hline None & 8,588 & 52.0 \\
\hline$\geq 1$ & 7,937 & 48.0 \\
\hline \multicolumn{3}{|l|}{ Number of Injuries $^{\dagger}$} \\
\hline 1 & 8,911 & 53.9 \\
\hline $2-4$ & 5,371 & 32.5 \\
\hline$\geq 5$ & 2,243 & 13.6 \\
\hline \multicolumn{3}{|l|}{ Tinnitus ${ }^{\ddagger}$} \\
\hline No & 14,245 & 86.2 \\
\hline Yes & 2,280 & 13.8 \\
\hline \multicolumn{3}{|c|}{$\begin{array}{l}\text { *43 missing date of injury. } \\
{ }^{*} \text { Number of injuries overall per person, resulting from } \geq 1 \text { injury events during } \\
\text { deployment. } \\
{ }^{\ddagger} \text { Any in-theater medical record or inpatient or outpatient medical visit with tin- } \\
\text { nitus diagnosis from } 2001 \text { to } 2013 \text { (ICD-9 diagnostic codes } 959.09,388.3 \text {, } \\
388.31 \text {, or } 388.32 \text { or AIS code } 240205.1 \text { ). } \\
\text { AIS = Abbreviated Injury Scale, E = enlisted, ICD-9 = International Classifica- } \\
\text { tion of Diseases-9th Revision. }\end{array}$} \\
\hline
\end{tabular}

face, and limbs and internal organ injuries such as traumatic brain injury. Nonbattle injuries were mostly upperand lower-limb injuries such as strains, sprains, and contusions. The majority of injuries in the battle injury and 


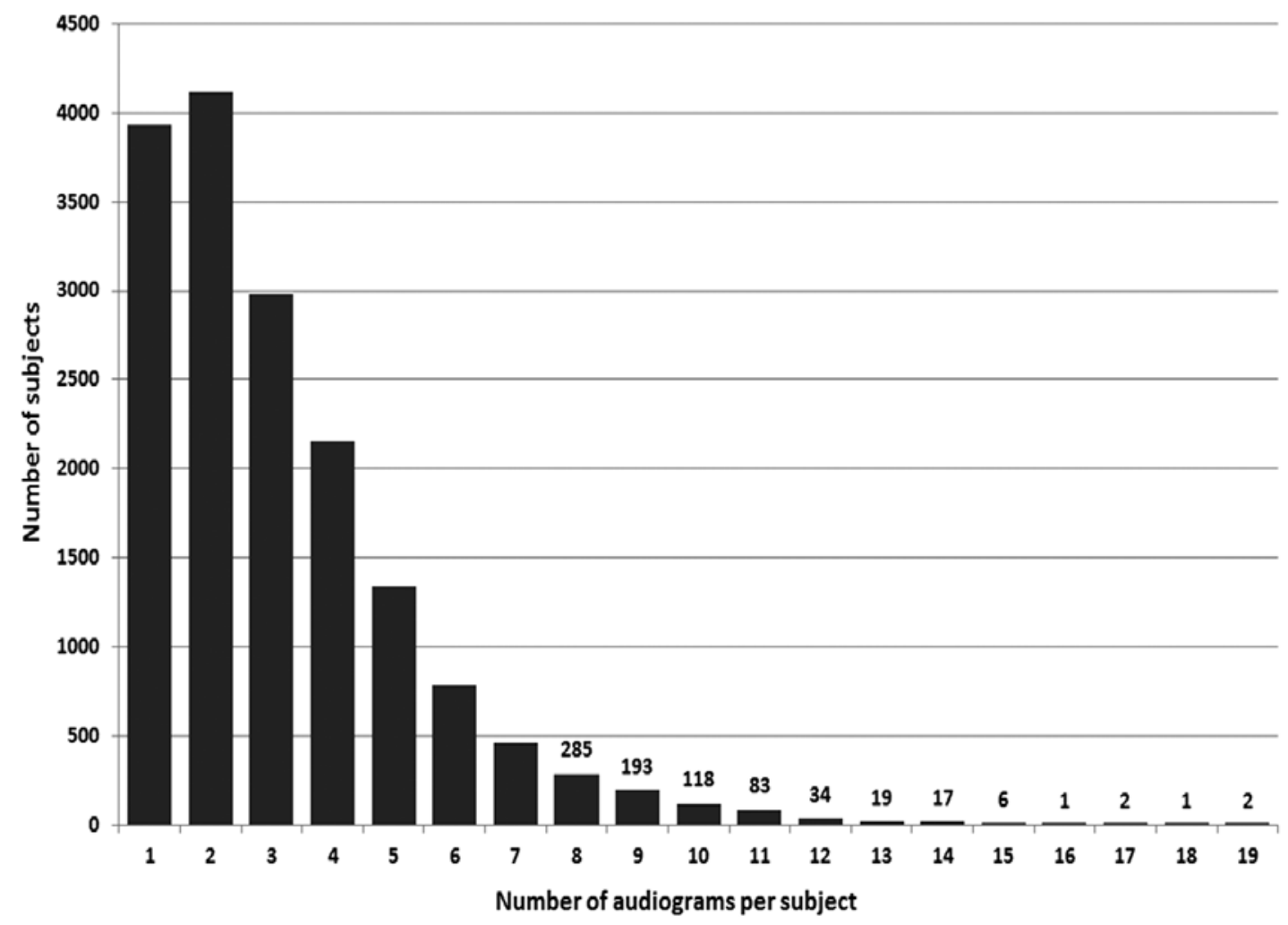

Figure 1.

Distribution of the count of qualified audiometric records per subject.

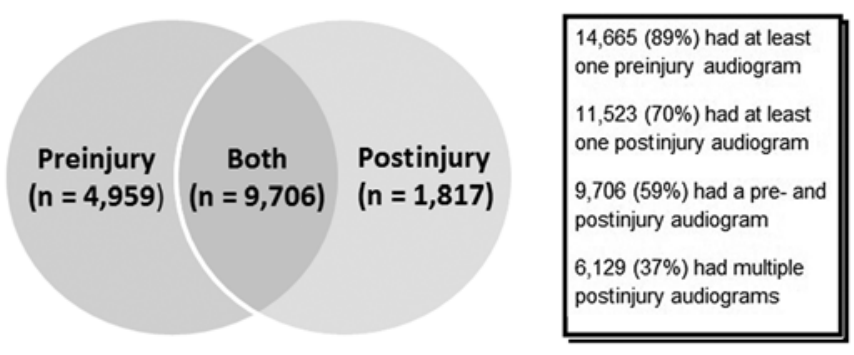

Figure 2.

Frequencies and proportions of deployment-injured Navy and Marine Corps personnel in the Blast-Related Auditory Injury Database with pre- and postinjury audiograms $(N=16,482 ; 43$ subjects were missing injury date and could not be included in the Venn diagram).

nonbattle injury groups consisted of minor to moderate injuries as defined by the AIS (90\% vs $98 \%$ ); however, nonbattle injuries were significantly less severe, with less than 2 percent of injuries classified as serious or worse compared with 10 percent for the battle-injury group.

Examination of the hearing threshold data in the BRAID, regardless of injury time, generated a description of hearing loss laterality, severity, and configuration (Table 3). Among those injured servicemembers with qualified audiometric data $(n=16,525), 39$ percent of subjects demonstrated hearing loss on at least one of their audiograms, 19 percent showed bilateral hearing loss, and 13 and 7 percent had left- and right-unilateral hearing loss, respectively. Using PTA calculations, low-frequency 
Table 2.

Descriptive statistics of all 42,034 deployment injuries incurred by 16,525 servicemembers included in the Blast-Related Auditory Injury Database.

\begin{tabular}{|c|c|c|c|c|c|}
\hline & \multicolumn{2}{|c|}{ Battle Injuries $(N=29,556)$} & \multirow[b]{2}{*}{$n$} & \multirow[b]{2}{*}{$\%$} & \multirow{2}{*}{$\begin{array}{c}\chi^{2} \\
p \text {-Value }\end{array}$} \\
\hline & $n$ & $\%$ & & & \\
\hline AIS Severity ${ }^{\dagger}$ & & & & & $<0.001$ \\
\hline Minor & 19,341 & 68.0 & 8,594 & 84.8 & \\
\hline Moderate & 6,317 & 22.2 & 1,376 & 13.6 & \\
\hline Serious & 2,070 & 7.3 & 130 & 1.3 & \\
\hline Severe & 475 & 1.7 & 26 & 0.3 & \\
\hline Fractures & 4,186 & 14.7 & 997 & 9.8 & \\
\hline Dislocation & 271 & 1.0 & 320 & 3.2 & \\
\hline Sprains and Strains & 1,205 & 4.2 & 4,144 & 40.8 & \\
\hline Internal Organ & 5,129 & 18.0 & 503 & 5.0 & \\
\hline Open Wound & 8,978 & 31.5 & 1,481 & 14.6 & \\
\hline Crushing & 7 & 0.0 & 16 & 0.2 & \\
\hline Burns & 1,065 & 3.7 & 400 & 3.9 & \\
\hline Nerves & 830 & 2.9 & 181 & 1.8 & \\
\hline Unspecified & 1,958 & 6.9 & 35 & 0.3 & \\
\hline System-wide and Late Effects & 129 & 0.5 & 85 & 0.8 & \\
\hline Injury Site ${ }^{\S}$ & & & & & $<0.01$ \\
\hline Traumatic Brain Injury & 4,345 & 15.3 & 458 & 4.5 & \\
\hline Other Head, Neck, Face & 7,807 & 27.4 & 1,281 & 12.6 & \\
\hline Spinal Cord & 54 & 0.2 & 7 & 0.1 & \\
\hline Vertebral Column & 1,203 & 4.2 & 1,286 & 12.7 & \\
\hline Torso & 3,081 & 10.8 & 446 & 4.4 & \\
\hline
\end{tabular}

hearing loss was identified in approximately 9 percent of the study population, while high-frequency hearing loss was evident in almost 22 percent of these subjects. There was a higher percentage of high-frequency hearing loss in the left ear (9.2\%) than the right ear (4.6\%). PTAs were significantly higher in the left ear than the right ear $(p<$ 0.001 ), and high-frequency PTAs were significantly higher than low frequencies for both ears $(p<0.001)$. Subjects with low-frequency hearing loss predominantly had bilateral hearing loss (46\%) or loss in the left ear only (33\%), and personnel with high-frequency hearing loss showed a preponderance of unilateral impairment (63\%), with unilateral left-ear hearing loss evident in 42 percent of those with high-frequency loss (percentages derived from Table 3).

\section{DISCUSSION}

The purpose of this study was to develop a long-standing and integrated capability for the surveillance, assessment, and investigation of blast-related hearing outcomes. At the 
Table 3.

Hearing loss and other outcomes calculated by available audiometric data from 2001 to 2013 of deployment-injured Navy and Marine Corps personnel $(N=16,525)$.

\begin{tabular}{|c|c|c|}
\hline Outcome & $n$ & $\%$ \\
\hline None & 10,056 & 60.9 \\
\hline Any & 6,469 & 39.1 \\
\hline Bilateral & 3,187 & 19.3 \\
\hline Left Ear Unilateral & 2,070 & 12.5 \\
\hline Right Ear Unilateral & 1,212 & 7.3 \\
\hline \multicolumn{3}{|c|}{ Low-Frequency Hearing Loss (>25 dB LFPTA*) } \\
\hline None & 15,102 & 91.4 \\
\hline Any & 1,423 & 8.6 \\
\hline Bilateral & 653 & 4.0 \\
\hline Left Ear Unilateral & 470 & 2.8 \\
\hline Right Ear Unilateral & 300 & 1.8 \\
\hline \multicolumn{3}{|c|}{ High-Frequency Hearing Loss $\left(>25 \mathrm{~dB} \mathrm{HFPTA}^{\dagger}\right.$ ) } \\
\hline None & 12,889 & 78.0 \\
\hline Any & 3,636 & 22.0 \\
\hline Bilateral & 1,356 & 8.2 \\
\hline Left Ear Unilateral & 1,520 & 9.2 \\
\hline Right Ear Unilateral & 760 & 4.6 \\
\hline \multicolumn{3}{|c|}{$\begin{array}{l}\text { Note: Any }=\text { hearing loss on any audiogram including baseline, predeploy- } \\
\text { ment, or postdeployment audiogram. } \\
{ }^{*} \text { Low-frequency pure-tone average (LFPTA) based on the average of the first } \\
\text { three frequencies ( } 500,1,000 \text {, and } 2,000 \mathrm{~Hz} \text { ) of all valid audiograms. } \\
{ }^{\dagger} \text { High-frequency pure-tone average }(\mathrm{HFPTA}) \text { based on the average of the last } \\
\text { three frequencies }(3,000,4,000 \text {, and } 6,000 \mathrm{~Hz} \text { ) of all valid audiograms. }\end{array}$} \\
\hline
\end{tabular}

time of this report, the BRAID was composed of primarily male, junior to midlevel enlisted, Active Duty Marine Corps personnel. After matching EMED and DOEHRSDR data and removing audiograms that met exclusionary criteria (4\%), 92 percent of the original audiograms were retained, thus our database comprised 51,516 audiograms from 16,525 servicemembers. This retention rate compares favorably with a large prevalence study conducted by Masterson et al. that retained 74 percent of the original test data [39]. Development of the BRAID identified that approximately 97 percent of deployment-injured Navy and Marine Corps personnel had at least one audiogram in the DOEHRS-DR system. A total of 89 percent of our cohort with an injury had preinjury audiometric tests available in the DOEHRS-DR system and 70 percent had postinjury data, providing us a large sample set of injured servicemembers with audiograms for future analysis. For comparison, a study conducted by Cave et al. indicated that 63 percent of their sample of 258 blast-injured patients had a predeployment audiogram [13]. Given the noise hazards prevalent in combat settings, it is critical that deployers obtain a monitoring audiogram before and after deployment.

Our findings on causality and types of battle injuries are consistent with other studies [7,40-42]. In general, the most common audiologic symptoms reported in victims of blast are tinnitus and hearing loss, with a significant proportion of patients reporting concomitant tinnitus and hearing loss. The rate of documented self-reported tinnitus in the BRAID was 13.8 percent, which approximates the national rate of 10 percent [43], and is far lower than the tinnitus rates reported in other blast-exposure studies. Assessing progression of audiologic symptoms is of primary importance in determining hearing-related morbidity. Previous studies have reported variable, but generally higher, rates of combat and blast-related hearing loss when compared with the BRAID. For example, in an investigation of deployed military personnel, Cave et al. found that approximately 50 percent of their subjects demonstrated persistent hearing loss [13]. These investigators attributed this higher rate to the fact that their data were extracted from an audiology clinic database. Previous studies have analyzed definitive clinical data, whereas we have examined occupational hearing conservation screening data. Military and civilian otologic and audiometric outcome data are inherently different, primarily because of the putative penultimate circumstance of the blast [26].

It is difficult to compare studies because some report the number of subjects, the number of ears, or both, and a variety of audiometric interpretations of "normal hearing" have been used. Our investigation identified a rate of hearing loss of 39 percent using octave-band audiometric threshold data, and a clinical definition of normal hearing as $\leq 25 \mathrm{~dB} \mathrm{HL}$ at all frequencies. Our hearing loss rate decreased from 39 to 23 percent when PTA threshold data instead of individual frequency threshold data were used as a clinical metric (for low and high frequencies). Our PTA rate (23\%) was similar to the national estimate of hearing loss (20\%) in the population reported by Lin et al. [44]. A need for further expansion and exploration of the BRAID is indicated.

\section{Study Strengths}

The EMED serves as a comprehensive, deploymenthealth database that contains records of forwarddeployed military personnel who receive medical treatment in theater for combat-related injury, noncombat injury, disease, psychiatric conditions, and routine care 
$[36,42,45]$. The EMED is both retrospective and prospective; however, its inclusion of accurate dates of injury provides a platform for prospective studies on hearing loss outcomes of blast injury, including establishment of preinjury baseline and temporality. The BRAID is an extensive database with large applications to many areas of future research in the occupational hearing health of military personnel. Baseline audiograms and multiple follow-up audiograms will allow for the surveillance of hearing shifts and observation of symptom patterns over time. The prospective nature of career, medical, and audiometric data of military personnel is a major strength because temporal associations of exposure and outcome relationships can be established. Subjects with multiple audiograms will provide data for further analyses of audiometric outcomes in future investigations. The large sample size of the BRAID affords sufficient power to detect differences in subgroups in future studies. Given that the permanent characteristics of auditory injury cannot be established until $1 \mathrm{yr}$ after a blast-exposure event [9], the BRAID may be the first large dataset with prognostic audiometric viability. In addition, inclusion of additional personnel records may provide researchers the ability to adjust for multiple confounders.

\section{Study Limitations}

In this data manipulation, we could not control for confounders such as cochleotoxic medications, exposures to ototoxic chemicals, recreational noise exposure, and other forms of temporary and persistent threshold shift. Combat marines and sailors are required to qualify with various firearms prior to and, in some cases, during deployment, regardless of military occupation code. It is challenging to confirm the protected exposure levels of subjects and the frequency of exposures on the firing range. This condition may serve as a confounding variable for audiometric threshold data. No Army or Air Force data were available for analysis, and no audiometric data were included that characterize hearing for Veterans following separation or retirement. In addition, the EMED only includes injury records for servicemembers who present for care.

\section{CONCLUSIONS}

The deployment setting represents an unusual work environment that introduces risks to the hearing health and safety of military personnel. It is apparent that DOD directives should be revised to include guidance regarding combat noise exposure, requirements for audiometric screening immediately before and after combat operations, and funding for hearing loss prevention. A prudent set of recommendations for combat-inclusive HCP administrators was published by Abel [46]. Hearing preservation research was identified as a top seven research initiative for the Surgeon General of the Navy Bureau of Medicine and Surgery during the Military Health System Research Symposium in August 2012. In the same year, at an annual DOD Hearing Center of Excellence meeting, epidemiologic investigations of military populations were specified as a significant research gap. We anticipate that the BRAID will have multiple applications, including to (1) examine audiometric data pre- and postblast injury event to discover associated hearing outcomes; (2) refine our framework for quality control of audiometric data; (3) bolster audiometric early flags for combat-related hearing loss; (4) determine health factors that predict threshold shifts and the degree to which symptoms resolve or continue over time; and (5) answer other important research questions about hearing loss, blast exposure, hearing protection performance, and the combined effect of these variables on situational awareness in the field of battle.

\section{ACKNOWLEDGMENTS}

\section{Author Contributions:}

Study concept and design: A. R. Joseph, J. L. Horton, M. C. Clouser, A. J. MacGregor, M. Louie.

Data acquisition: M. R. Galarneau.

Data management: M. Louie.

Analysis and interpretation of data: A. R. Joseph, J. L. Horton, M. C. Clouser.

Drafting of manuscript: A. R. Joseph.

Critical revision of manuscript for important intellectual content:

J. L. Horton, M. C. Clouser, A. J. MacGregor, M. R. Galarneau.

Obtained funding: M. R. Galarneau.

Administrative support: M. R. Galarneau.

Financial Disclosures: The authors have declared that no competing interests exist.

Funding/Support: This material was based on work supported by the U.S. Navy Bureau of Medicine and Surgery Wounded, Ill, and Injured Program (work unit 60808).

Additional Contributions: In addition to the study team, we thank the Naval Health Research Center, and particularly Carrie Brown and Michelle LeWark, for thorough technical review and support. This material represents Report 15-05, supported by the DOD, under work unit no. 60808 of the U.S. Navy Bureau of Medical and Surgery 
Wounded, Ill, and Injured Program. Antony R. Joseph, AuD, PhD, has changed affiliations since completion of this study: Communication Sciences and Disorders, Illinois State University, Normal, Illinois. Michelle Louie, AuD, gained credentials since completion of the study: Doctor of Audiology, California State University San Diego, San Diego, California.

Institutional Review: This research has been conducted in compliance with all applicable Federal regulations governing the protection of human subjects in research (protocol NHRC.2003.0025).

Participant Follow-Up: No participants were informed of the publication of this aggregated information because contact information was unavailable.

Disclaimer: The views expressed in this article are those of the authors and do not reflect the official policy or position of the Department of the Navy, DOD, or the U.S. Government.

\section{REFERENCES}

1. Tak S, Davis RR, Calvert GM. Exposure to hazardous workplace noise and use of hearing protection devices among US workers-NHANES, 1999-2004. Am J Ind Med. 2009;52(5):358-71. [PMID:19267354]

http://dx.doi.org/10.1002/ajim.20690

2. U.S. Department of Defense (DOD). Department of Defense Instruction-Number 6055.12: Hearing Conservation Program (HCP) [Internet]. Washington (DC): DOD; Dec 2010 [cited 2015 Mar]. Available from: http://dtic.mil/ whs/directives/corres/pdf/605512p.pdf

3. Occupational Safety and Health Administration (OSHA). Occupational noise exposure; Hearing conservation amendment [Internet]. Washington (DC): OSHA; 1983 [cited 2015 Mar]. Available from: https://www.osha.gov/pls/oshaweb/owastand.display_standard_group?p_toc_level=1\&p_part_number=1 $\underline{910}$

4. Heupa AB, Gonçalves CG, Coifman H. Effects of impact noise on the hearing of military personnel. Braz J Otorhinolaryngol. 2011;77(6):747-53. [PMID:22183281] http://dx.doi.org/10.1590/S1808-86942011000600011

5. Hirsch FG. Effects of overpressure on the ear-a review. Ann N Y Acad Sci. 1968;152(1):147-62. [PMID:4896232] http://dx.doi.org/10.1111/j.1749-6632.1968.tb11972.x

6. Kerr AG. Blast injuries to the ear. Practitioner. 1978; 221(1325):677-82. [PMID:740613]

7. Lew HL, Jerger JF, Guillory SB, Henry JA. Auditory dysfunction in traumatic brain injury. J Rehabil Res Dev. 2007; 44(7):921-28. [PMID:18075949] http://dx.doi.org/10.1682/JRRD.2007.09.0140

8. Van Campen LE, Dennis JM, Hanlin RC, King SB, Velderman AM. One-year audiologic monitoring of individuals exposed to the 1995 Oklahoma City bombing. J Am Acad Audiol. 1999;10(5):231-47. [PMID:10331616]
9. Nageris BI, Attias J, Shemesh R. Otologic and audiologic lesions due to blast injury. J Basic Clin Physiol Pharmacol. 2008;19(3-4):185-91. [PMID:19025030]

http://dx.doi.org/10.1515/JBCPP.2008.19.3-4.185

10. Centers for Disease Control and Prevention (CDC). Blast injuries: Essential facts [Internet]. Atlanta (GA): CDC; 2008 May 12 [cited 2010 June 28]. Available from:

http://www.bt.cdc.gov/masscasualties/pdf/blastinjuries.pdf

11. Phillips YY, Zajtchuk JT. Blast injuries of the ear in military operations. Ann Otol Rhinol Laryngol Suppl. 1989; 140:3-4. [PMID:2497696]

12. Shupak A, Doweck I, Nachtigal D, Spitzer O, Gordon CR. Vestibular and audiometric consequences of blast injury to the ear. Arch Otolaryngol Head Neck Surg. 1993;119(12): 1362-67. [PMID:17431991] http://dx.doi.org/10.1001/archotol.1993.01880240100013

13. Cave KM, Cornish EM, Chandler DW. Blast injury of the ear: Clinical update from the global war on terror. Mil Med. 2007;172(7):726-30. [PMID:17691685] http://dx.doi.org/10.7205/MILMED.172.7.726

14. Chait RH, Casler J, Zajtchuk JT. Blast injury of the ear: Historical perspective. Ann Otol Rhinol Laryngol Suppl. 1989;140:9-12. [PMID:2497701]

15. Garth RJ. Blast injury of the auditory system: A review of the mechanisms and pathology. J Laryngol Otol. 1994; 108(11):925-29. [PMID:7829942] http://dx.doi.org/10.1017/S0022215100128555

16. Yetiser S, Ustun T. Concussive blast-type aural trauma, eardrum perforations, and their effects on hearing levels: An update on military experience in Izmir, Turkey. Mil Med. 1993;158(12):803-6. [PMID:8108023]

17. Ziv M, Philipsohn NC, Leventon G, Man A. Blast injury of the ear: Treatment and evaluation. Mil Med. 1973;138(12): 811-13. [PMID:4203609]

18. Bruins WR, Cawood RH. Blast injuries of the ear as a result of the Peterborough lorry explosion: 22 March 1989. J Laryngol Otol. 1991;105(11):890-95. [PMID:1761940] http://dx.doi.org/10.1017/S002221510011775X

19. Chandler DW, Edmond CV. Effects of blast overpressure on the ear: Case reports. J Am Acad Audiol. 1997;8(2):81-88. [PMID:9101454]

20. Fausti SA, Wilmington DJ, Helt PV, Helt WJ, Konrad-Martin D. Hearing health and care: The need for improved hearing loss prevention and hearing conservation practices. J Rehabil Res Dev. 2005;42(4 Suppl 2):45-62.

[PMID:16470464] http://dx.doi.org/10.1682/JRRD.2005.02.0039

21. Singh D, Ahluwalia KJ. Blast injuries of the ear. J Laryngol Otol. 1968;82(11):1017-28. [PMID:5686416] http://dx.doi.org/10.1017/S0022215100069802

22. Teter DI, Newell RC, Aspinall KB. Audiometric configurations associated with blast trauma. Laryngoscope. 1970; 
80(7):1122-32. [PMID:5450302]

http://dx.doi.org/10.1288/00005537-197007000-00010

23. Walsh RM, Pracy JP, Huggon AM, Gleeson MJ. Bomb blast injuries to the ear: The London Bridge incident series. J Accid Emerg Med. 1995;12(3):194-98. [PMID:8581246] http://dx.doi.org/10.1136/emj.12.3.194

24. Kerr AG, Byrne JE. Surgery of violence. IV. Blast injuries of the ear. BMJ. 1975;1(5957):559-61. [PMID:1139149] http://dx.doi.org/10.1136/bmj.1.5957.559

25. Shah A, Ayala M, Capra G, Fox D, Hoffer M. Otologic assessment of blast and nonblast injury in returning Middle East-deployed service members. Laryngoscope. 2014;124(1): 272-77. [PMID:23686673] http://dx.doi.org/10.1002/lary.24169

26. Remenschneider AK, Lookabaugh S, Aliphas A, Brodsky JR, Devaiah AK, Dagher W, Grundfast KM, Heman-Ackah SE, Rubin S, Sillman J, Tsai AC, Vecchiotti M, Kujawa SG, Lee DJ, Quesnel AM. Otologic outcomes after blast injury: The Boston Marathon experience. Otol Neurotol. 2014; 35(10):1825-34. [PMID:25393974] http://dx.doi.org/10.1097/MAO.0000000000000616

27. Mrena R, Pääkkönen R, Bäck L, Pirvola U, Ylikoski J. Otologic consequences of blast exposure: A Finnish case study of a shopping mall bomb explosion. Acta Otolaryngol. 2004;124(8):946-52. [PMID:15513532] http://dx.doi.org/10.1080/00016480310017045

28. Folmer RL, Billings CJ, Diedesch-Rouse AC, Gallun FJ, Lew HL. Electrophysiological assessments of cognition and sensory processing in TBI: Applications for diagnosis, prognosis and rehabilitation. Int J Psychophysiol. 2011; 82(1):4-15. [PMID:21419179] http://dx.doi.org/10.1016/j.ijpsycho.2011.03.005

29. Lew HL, Otis JD, Tun C, Kerns RD, Clark ME, Cifu DX. Prevalence of chronic pain, posttraumatic stress disorder, and persistent postconcussive symptoms in OIF/OEF veterans: Polytrauma clinical triad. J Rehabil Res Dev. 2009; 46(6):697-702. [PMID:20104399] http://dx.doi.org/10.1682/JRRD.2009.01.0006

30. Lew HL, Pogoda TK, Baker E, Stolzmann KL, Meterko M, Cifu DX, Amara J, Hendricks AM. Prevalence of dual sensory impairment and its association with traumatic brain injury and blast exposure in OEF/OIF veterans. J Head Trauma Rehabil. 2011;26(6):489-96. [PMID:21386715] http://dx.doi.org/10.1097/HTR.0b013e318204e54b

31. Oleksiak M, Smith BM, St Andre JR, Caughlan CM, Steiner M. Audiological issues and hearing loss among Veterans with mild traumatic brain injury. J Rehabil Res Dev. 2012;49(7):995-1004. [PMID:23341275] http://dx.doi.org/10.1682/JRRD.2011.01.0001

32. U.S. Department of Veterans Affairs Veterans Benefits Administration. Annual Benefits Report Fiscal Year 2012 [Internet]. Washington (DC): VA VBA; 2013 Jun [cited
2015 Mar]. 166 p. Available from: http://benefits.va.gov/ REPORTS/abr/2012 abr.pdf

33. Henry JL. [Presentation]. Department of Defense (DOD) and Department of Veterans Affairs Auditory Research Working Group sponsored by the DOD Hearing Center of Excellence; 2012; Dayton, $\mathrm{OH}$.

34. Tufts JB, Weathersby PK, Rodriguez FA. Modeling the United States government's economic cost of noiseinduced hearing loss for a military population. Scand J Work Environ Health. 2010;36(3):242-49.

[PMID:20339823]

http://dx.doi.org/10.5271/sjweh.2911

35. World Health Organization (WHO). Prevention of noiseinduced hearing loss [Internet]. Geneva (Switzerland): WHO; 1997 [cited 2015 Mar]. 55 p. Available from: http://www.who.int/pbd/deafness/en/noise.pdf

36. Galarneau MR, Hancock WC, Konoske P, Melcer T, Vickers RR, Walker GJ, Zouris JM. The Navy-Marine Corps Combat Trauma Registry. Mil Med. 2006;171(8):691-97. [PMID:16933807] http://dx.doi.org/10.7205/MILMED.171.8.691

37. American National Standards Institute (ANSI). ANSI S:3.6-1996: Specification for audiometers. New York (NY): Acoustical Society of America; 1996.

38. Dougherty AL, MacGregor AJ, Han PP, Viirre E, Heltemes KJ, Galarneau MR. Blast-related ear injuries among U.S. military personnel. J Rehabil Res Dev. 2013;50(6):893-904. [PMID:24030196] http://dx.doi.org/10.1682/JRRD.2012.02.0024

39. Masterson EA, Tak S, Themann CL, Wall DK, Groenewold MR, Deddens JA, Calvert GM. Prevalence of hearing loss in the United States by industry. Am J Ind Med. 2013; 56(6):670-81. [PMID:22767358] http://dx.doi.org/10.1002/ajim.22082

40. MacGregor AJ, Dougherty AL, Morrison RH, Quinn KH, Galarneau MR. Repeated concussion among U.S. military personnel during Operation Iraqi Freedom. J Rehabil Res Dev. 2011;48(10):1269-78. [PMID:22234670] http://dx.doi.org/10.1682/JRRD.2011.01.0013

41. MacGregor AJ, Shaffer RA, Dougherty AL, Galarneau MR, Raman R, Baker DG, Lindsay SP, Golomb BA, Corson KS. Prevalence and psychological correlates of traumatic brain injury in operation iraqi freedom. J Head Trauma Rehabil. 2010;25(1):1-8. [PMID:20051901] http://dx.doi.org/10.1097/HTR.0b013e3181c2993d

42. Wade AL, Dye JL, Mohrle CR, Galarneau MR. Head, face, and neck injuries during Operation Iraqi Freedom II: Results from the US Navy-Marine Corps Combat Trauma Registry. J Trauma. 2007;63(4):836-40. [PMID:18090014] http://dx.doi.org/10.1097/01.ta.0000251453.54663.66

43. Kochkin S, Tyler R, Born J. MarkeTrak VIII: The prevalence of tinnitus in the United States and the self-reported 
efficacy of various treatments. Hearing Review. 2011; 18:10-27.

44. Lin FR, Niparko JK, Ferrucci L. Hearing loss prevalence in the United States. Arch Intern Med. 2011;171(20):1851-52. [PMID:22083573] http://dx.doi.org/10.1001/archinternmed.2011.506

45. MacGregor AJ, Corson KS, Larson GE, Shaffer RA, Dougherty AL, Galarneau MR, Raman R, Baker DG, Lindsay SP, Golomb BA. Injury-specific predictors of posttraumatic stress disorder. Injury. 2009;40(9):1004-10. [PMID:19524912] http://dx.doi.org/10.1016/j.injury.2009.04.006

46. Abel SM. Barriers to hearing conservation programs in combat arms occupations. Aviat Space Environ Med. 2008; 79(6):591-98. [PMID:18581943] http://dx.doi.org/10.3357/ASEM.2262.2008

Submitted for publication March 3, 2015. Accepted in revised form July 21, 2015.
This article and any supplementary material should be cited as follows:

Joseph AR, Horton JL, Clouser MC, MacGregor AJ, Louie M, Galarneau MR. Development of a comprehensive Blast-Related Auditory Injury Database (BRAID). J Rehabil Res Dev. 2016;53(3):295-306.

http://dx.doi.org/10.1682/JRRD.2015.02.0031

ORCID: Antony R. Joseph, AuD, PhD: 0000-0001-7740620X; Jaime L. Horton, MPH: 0000-0001-9212-178X; Mary C. Clouser, MPH, PhD: 0000-0001-6929-4412

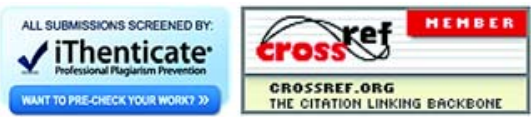

